\title{
Natural history and prognosis of diarrhoea of unknown cause in patients with acquired immunodeficiency syndrome (AIDS)
}

\author{
C Blanshard, B G Gazzard
}

\begin{abstract}
This paper is a prospective study of patients with advanced human immunodeficiency virus infection and chronic diarrhoea for which no cause could be found after extensive investigations, including examination of multiple stool specimens for all known faecal pathogens and the histological examination of small and large bowel biopsy specimens. Of 39 such patients recruited from 155 prospectively investigated patients, eight had a possible cause of diarrhoea identified on follow up investigations, including small bowel neoplasms in three and cytomegalovirus in two. In 17 of the remaining 31 the diarrhoea resolved completely in a mean of seven months from its onset. Eleven had continuing mild or intermittent diarrhoea and three had more than 1 litre of diarrhoea daily for which no cause could be found. The median survival for patients with 'pathogen negative' diarrhoea was $48 \cdot 7$ months, which is similar to that of control patients with no diarrhoea and significantly longer than that of matched patients with a gastrointestinal pathogen (9.6 months).

(Gut 1995; 36: 283-286)
\end{abstract}

Keywords: AIDS, diarrhoea.

Previous studies of diarrhoea in human immunodeficiency virus (HIV) seropositive patients have identified a number of patients in whom no cause for the diarrhoea could be found. ${ }^{1-4}$ The simplest explanation for this is that the investigations carried out fail to identify a proportion of the pathogens present. Alternatively the diarrhoea may be caused by a novel pathogen or by a gut autonomic neuropathy, ${ }^{56}$ bacterial overgrowth ${ }^{67}$ or flat mucosa induced by HIV infection of the gut mucosa. ${ }^{8}$ If this last mechanism was important, the diarrhoea would not be expected to resolve and might well become worse as HIV infection progressed. Little is known, however, about the outcome and prognosis of diarrhoea in these patients.

We recruited a cohort of patients with apparently 'pathogen negative' diarrhoea and performed further investigations to identify possible pathogens that had been missed initially. We then followed them up prospectively to assess the outcome of the diarrhoea, and compared their survival to two groups of contemporaneously recruited controls: patients with a known pathogen and subjects without diarrhoea.

\section{Methods}

\section{PATIENTS}

Patients all of whom had a CD4 lymphocyte count of less than 200 cells $/ \mathrm{mm}^{3}$ were drawn from a cohort of 155 patients who had been recruited as part of a prospective study of diarrhoea (defined as three or more liquid motions per day for at least one month). No cause for diarrhoea had been identified after a series of investigations.

\section{Microbiology}

Six stool specimens were cultured for faecal pathogens on salmonella/shigella agar medium, campylobacter selective medium and selanite $F$ enrichment medium and Lowenstein-Jensen slopes for mycobacteria. Concentrated wet preparations from each specimen were examined by direct microscopy for ova, cysts, and parasites. Smears were stained with auramine-phenol for cryptosporidia with confirmation by a modified acid fast method.

At least one concentrated preparation was prepared and examined for cryptosporidia if six standard preparations were negative.

A cytotoxicity assay for Clostridium difficile toxin was performed on one stool sample.

Blood from febrile patients was cultured for mycobacteria and other pathogens using a $\mathrm{C}^{14}$ radiometric method (Bactec; Becton Dickinson Diagnostic Instrument Systems, Tucson, Maryland, USA).

\section{Virology}

Three specially prepared stool specimens were examined for viral particles using electron microscopy and a commercial rotavirus latex test.

\section{Histopathology}

Samples for histological examination were obtained at upper gastrointestinal endoscopy. Duodenal fluid was aspirated into a sterile containers after discarding the first 2-3 ml. Pinch biopsy specimens were taken from random sites in the distal part of the duodenum and jejunal biopsy specimens beyond the ligament of Trietz were obtained with a 
Crosby capsule. These were used to produce five impression smears, which were stained with Giemsa.

Sigmoidoscopy was also performed and specimens were taken from any areas of macroscopic abnormality, and from three standard sites: $12 \mathrm{~cm}$ anteriorly, $12 \mathrm{~cm}$ posteriorly, and $8 \mathrm{~cm}$ posteriorly.

All histological samples were examined using haematoxylin and eosin, periodic acid Schiff (PAS), PAS-diastase, Zeihl-Neelsen, and an immunoperoxidase stain for cytomegalovirus (CMV). In addition, immunocytochemical staining for adenovirus was carried out on the rectal biopsy specimens using adenovirus primary antibody (Serotec No MCA 489). ${ }^{9}$

Gluteraldehyde fixed biopsy specimens were processed for electron microscopy. Sections $70 \mathrm{~nm}$ thick were stained with uranyl acetate and lead citrate and examined for viral and protozoal pathogens.

\section{FURTHER INVESTIGATIONS, TREATMENT, AND}

FOLLOW UP

Patients were reviewed at least monthly until the diarrhoea resolved, for a minimum of six months from presentation or until death. All had the following further investigations. (1) Six more stool specimens for culture, microscopy, virology, and for microsporidia spores using both Weber's strong trichrome method ${ }^{10}$ and a calcofluor stain. ${ }^{11}$ (2) Colonscopy with serial biopsies for light and electron microscopy. (3) Upper gastrointestinal endoscopy with duodenal biopsies and aspiration of duodenal fluid. (4) A barium follow through. (5) A 5 $\mathrm{gm} / \mathrm{d}$ Xylose absorption test and a two part Schilling test using standard methods.

Definitions used were: 'resolution' as a return to the patient's normal bowel habit for at least three months with passage of less than three stools daily and cessation of antidiarrhoeal treatment; 'intermittent diarrhoea' as episodes of diarrhoea lasting up to two weeks separated by up to three months; 'continuous mild diarrhoea' as three to five liquid or semiliquid stools daily on most days with symptoms controllable by antidiarrhoeal drugs such as loperamide, diphenoxylate or codeine phosphate; and 'continuous severe diarrhoea' as at least five liquid stools daily on most days with poor control by antidiarrhoeal drugs.

A cause of diarrhoea was defined if on at least one occasion a recognised opportunistic or non-opportunist pathogen was seen. We included within this definition a number of organisms whose pathogenicity is uncertain (see Table I). Small bowel lymphoma or Kaposi's sarcoma if it involved at least $30 \%$ of the visible small bowel or large bowel mucosa was also considered a cause of diarrhoea.

CASE CONTROL STUDY

For each patient two controls were identified matched for risk group, age, CD4 lymphocyte count $( \pm 10 \%)$, duration of AIDS ( \pm two
TABLE I Results of a prospective investigation of 155 patients with diarrhoea for >one month and a CD4 count of $<200 / \mathrm{mm}^{3}$

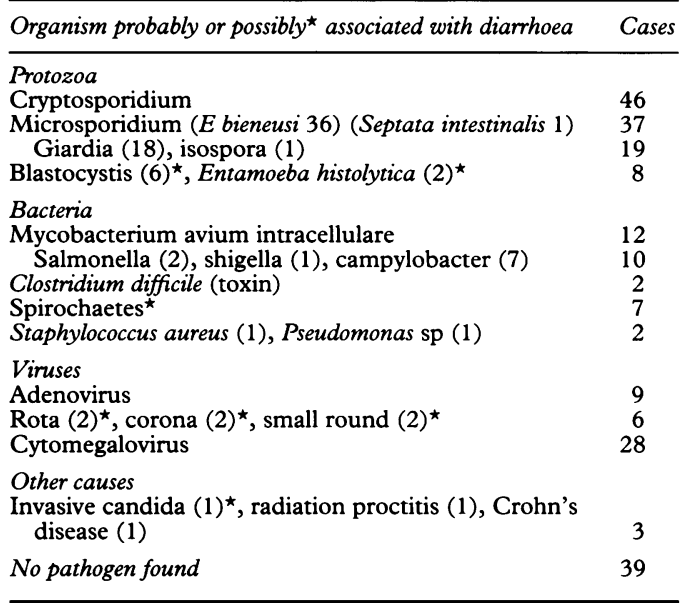

months), and year of AIDS diagnosis. Group A had diarrhoea caused by a recognised pathogen (cryptosporidium, microsporidium or CMV). Group B had no intestinal infection or diarrhoea.

The survival of those with diarrhoea was calculated from its onset and of group B controls from the date at which they had the corresponding CD4 count. Life table analysis was used to calculate the median survival times of each group and the survival of the groups was compared using the log rank test.

\section{Results}

Thirty nine of 155 patients investigated had pathogen negative diarrhoea (Table I) of whom 38 were homosexual men with a mean age $34 \cdot 7$ years (range 24-50), weight of $66 \cdot 1 \mathrm{~kg}$ (range 44-82), body mass index of $21 \mathrm{~kg} / \mathrm{m}^{2}$ (range 16.5-26.3), and CD4 count of $59 / \mathrm{mm}^{3}$ (range 3-191). Twenty eight had had a previous AIDS defining opportunistic infection and nine had cutaneous Kaposi's sarcoma. None was febrile. Many had colicky abdominal pain (21), worsening of the diarrhoea with eating (16), faecal incontinence (13), and urgency (16). Some patients had nausea (12), nocturnal diarrhoea (6), excessive mucus (4) or blood in the stool (2), and mild tenderness on abdominal palpation (4). The mean stool frequency was six per day and mean stool volume $593 \mathrm{ml}$. Twenty one patients were taking zidovudine and the two taking dideoxyinosine (ddI) had both stopped the drug for three weeks before presenting for investigation. Twenty one patients had been abroad in the three months before the onset of diarrhoea but in only two cases had the

TABLE II Relation between outcome of diarrhoea and weight change during follow up

\begin{tabular}{llll}
\hline \multirow{2}{*}{$\begin{array}{l}\text { Outcome of } \\
\text { diarrhoea }\end{array}$} & \multicolumn{3}{l}{ Weight change } \\
\cline { 2 - 4 } & Stabilised & Decreased & Increased \\
\hline Settled & 12 & 4 & 1 \\
Continued & 5 & 8 & 1 \\
Pathogen found & 0 & 8 & 0 \\
\hline
\end{tabular}

* Significant weight reduction compared with patients in whom diarrhoea settled $\left(\chi^{2 \star} 10 \cdot 1, p=0 \cdot 04\right)$. 


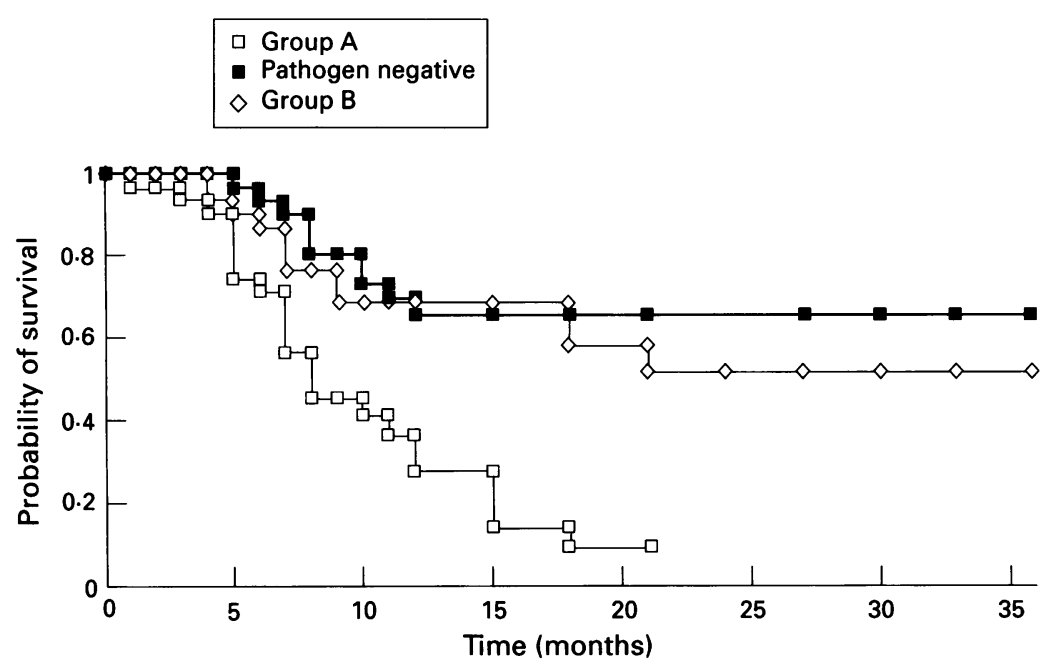

Kaplan-Meier survival curves for patients with pathogen negative diarrhoea who did not have an occult pathogen identified on further follow up ('pathogen negative') compared with control patients with a recognised gut pathogen (group $A$ ) and controls with no history of diarrhoea (group $B$ ). The median survival for the pathogen negative group, for group $A$, and group $B$ was $48 \cdot 7,9 \cdot 6$, and 48.2 months respectively. The survival of the pathogen negative group and group $B$ was significantly longer than that of group $A(p<0 \cdot 001)$.

diarrhoea started within a month of completing the trip.

After further investigations, a possible cause of diarrhoea was identified in eight patients (three malignant infiltration, two cytomegalovirus, one adenovirus, one microsporidial, and one cryptosporidial infection). There was no difference in most symptoms or CD4 lymphocyte count between patients who did and did not have a cause of diarrhoea identified. Weight continued to decrease, however, in those in whom a pathogen was uncovered compared with those in whom the diarrhoea eventually resolved (Table II).

CMV infection was found in three of these patients and the diarrhoea improved with ganciclovir treatment in two. One had inclusions in both colonic and small bowel biopsy specimens obtained three months after the initial biopsies and another had marked CMW gastritis. A third patient had a few CMV inclusions in caecal biopsy specimens and adenovirus infection of the left colon. His diarrhoea did not resolve after treatment with foscarnet.

Three patients were found to have malignant infiltration of the small bowel. In one patient with widespread cutaneous Kaposi's sarcoma the barium meal and follow through showed numerous fitting defects suggestive of Kaposi's sarcoma involving a substantial area of the small bowel and this was confirmed histologically. Two patients had small bowel lymphoma, diagnosed in one case at laparotomy after recurrent bouts of abdominal pain and pyrexia, and in a second at necropsy.

One patient was found to have microsporidiosis on his second set of duodenal biopsy specimens and in stool specimens.

The final patient in whom a pathogen was uncovered had diarrhoea that settled but he developed abdominal pain and cholangiographic evidence of AIDS related sclerosing cholangitis. Cryptosporidia were identified in bile, ampullary, and bile duct biopsy specimens.
Patients were reviewed for up to 30 months after initial investigations. In 17 of 31 with no cause for the diarrhoea, this resolved completely without subsequent recurrence in a mean of seven months (range 2-37 months). A further seven patients had mild daily diarrhoea, four had intermittent diarrhoea, and only three had severe diarrhoea. In these three patients, stool volumes were consistently more than a litre a day with little response to opiates. The diarrhoea persisted but decreased in volume (to less than $500 \mathrm{ml} /$ day) with fasting. All three continued to lose weight at a rate of 0.5 to $1 \mathrm{~kg}$ per month despite oral protein and energy supplements. They had five hour urinary xylose excretions of less than $10 \%$ and a B12 absorption of less than $8 \%$. All had therapeutic trials of metronidazole, ciprofloxacin, and foscarnet or ganciclovir without any improvement in their symptoms, and there was no change when all treatment was stopped for three weeks. All three have had small bowel enteroscopy performed using a paediatric colonoscope, and serial biopsy specimens showed no evidence of infection or neoplasia. Small bowel aspirates grew less than $10^{4}$ $\mathrm{CFU} / \mathrm{ml}$ of bacteria.

There was no difference in CD4 count, weight, stool frequency or volume or associated symptoms between those patients whose diarrhoea settled and those who had ongoing symptoms (Table II).

The survival for patients in whom no cause was found for the diarrhoea was similar to that of patients without diarrhoea (median 48 months) and significantly longer than that of patients with an opportunistic pathogen causing diarrhoea (9.6 months) (Figure).

\section{Discussion}

This is the first longitudinal prospective study of a group of HIV seropositive patients with diarrhoea in which no pathogen has been uncovered despite extensive investigations. We have found that in most patients the diarrhoea resolved spontaneously and only in $20 \%$ did a probable cause become apparent on subsequent investigation, most commonly, CMV infection or malignant infiltration of the small bowel.

The importance of $\mathrm{CMV}$ inclusions in a macroscopically normal colonic mucosa and in the upper gut of patients with diarrhoea is unclear but in two of three patients in whom this occurred, the diarrhoea improved with anti-CMV treatment and in a third patient, adenovirus was also found, which might have been responsible for the symptoms. The findings of only one case in which CMV inclusions were seen solely in caecal biopsy specimens, reinforces our previous view that colonoscopy has little advantage over sigmoidoscopy with biopsy in the diagnosis of AIDS related diarrhoea. ${ }^{12}$

Although malignant infiltration of the gut with Kaposi's sarcoma or lymphoma is common, this rarely causes diarrhoea. ${ }^{13} 14$ Small bowel enteroscopy, however, should be considered in patients with persistently 
negative diarrhoea to detect the occasional case.

The cause of the diarrhoea in the remaining 31 patients is unclear. There has been one previous report of diarrhoea and bacteraemia in an AIDS patient caused by enteroinvasive Echerichia colit ${ }^{15}$ and one of chronic diarrhoea and malabsorption thought to be caused by enteroadherent $E$ coli found attached to ileal and colonic enterocytes, which responded to ciprofloxacin. ${ }^{16}$ Although pathogenic subtypes of $E$ coli would not have been identified by our investigations, we do not believe this was the cause of diarrhoea as all those with persistent symptoms were treated with ciprofloxacin without benefit.

We do not routinely perform quantitative cultures of duodenal aspirate in our patients. Two small studies in HIV have found bacterial overgrowth, mainly of mouth flora, associated with gastric hypoacidity in HIV seropositive patients. ${ }^{67}$ In both these studies, overgrowth was not necessarily associated with diarrhoea and the numbers of organisms found was less than that seen in conditions such as tropical sprue and blind loop syndrome. The high rate of resolution of the diarrhoea in our patients without antibacterial drugs is against bacterial overgrowth being the cause of diarrhoea and the three patients with the most severe persisting diarrhoea had cultures of duodenal fluid that did not show infection.

Spontaneous resolution or easy symptomatic control of pathogen negative diarrhoea in HIV positive patients has been noted previously. 1718 Self limited chronic idiopathic diarrhoea has also been noted in immunocompetent subjects ${ }^{19}$ and has many similarities with that in our patients: blood and mucus in the stools, nausea, vomiting, and abdominal cramps were rare but urgency and incontinence occurred in about $30 \%$; most also had a history of recent travel abroad but family and household contacts were not affected.

The case control study shows that the patients with pathogen negative diarrhoea survive considerably longer than patients with a recognised gut pathogen, implying that they do not have an occult infection comparable with cryptosporidium, microsporidium or CMV. The presence of pathogen negative diarrhoea does not seem to adversely affect their prognosis compared with that of similar patients without diarrhoea. Patients may be reassured that providing known pathogens are rigorously excluded the diarrhoea will probably resolve or improve: only three patients, representing less than $2 \%$ of the original cohort, had severe daily diarrhoea that eluded diagnosis.

1 Antony MA, Brandt LJ, Klein RS, Bernstein LH. Infectious diarrhoea in patients with AIDS. Dig Dis Sci 1988; 9; 1141-6.

2 Colebunders $R$, Lusakamuni $K$, Nelson AM, Gigase P, Lebughe I, Van Marck E, et al. Persistant diarrhoea in Zairian AIDS patients: an endoscopic and histological study. Gut 1988; 29: 1687-91.

3 Connolly GM, Shanson D, Hawkins D, Harcourt, Webster IN, Gazzard BG. Non-cryptosporidial diarrhoea in human immunodeficiency virus (HIV) infected patients. Gut 1989; 30: 195-200.

4 Kotler DP, Gaetz HP, Lange M, Klein EB, Holt PR. Enteropathy associated with the acquired immunodeficiency syndrome. Ann Intern Med 1984; 101: 421-8.

5 Batman PA, Miller ARO, Sedgwick PM, Griffin GE Autonomic denervation of jejunal mucosa of homosexual men infected with HIV. AIDS 1991; 5: 1247-52.

6 Budhraja MD, Levendoglu H, Kocka F, Mangkornkanok $M$, Sherer R. Duodenal mucosal T cell subpopulation and bacterial cultures in acquired immunodeficiency syndrome. Am $\mathcal{f}$ Gastroenterol 1987; 82: 427-31.

7 Belitsos PC, Greenson JK, Yardley JH, Sisler J, Bartlett JG. Association of gastric hypoacidity with opportunistic Association of gastric hypoacidity with opportunistic 166: $277-84$.

8 Cummins AG, LaBrooy JT, Stanley DP, Rowland R, Shearman DJC. Quantitative histological study of enteropathy associated with HIV infection. Gut 1990; 31: 317-21.

9 Maddox A, Francis N, Moss J, Blanshard C, Gazzard BG. Adenovirus infection of the large bowel in HIV positive patients. F Clin Pathol 1992; 45: 684-8.

10 Weber R, Bryan RT, Owen RL, Wilcox CM, Gorelkin L, Visvesara GS. Improved light-microscopical detection of microsporidia spores in stools and duodenal aspirates. M Engl $₹$ Med 1992; 326: 161-6.

11 Van Gool R, Snijders F, Reiss P, Eeftinck Schattenkerk JKM, van den Bergh Weerman MA, Bartelsman JFWM, et al. Diagnosis of microsporidial infections in HIVinfected individuals with a new fluorescent technique. f Clin Pathol 1993; 46: 694-9.

12 Connolly GM, Forbes A, Gleeson JA, Gazzard BG. Value of barium enema and colonoscopy in HIV positive patients with diarrhoea. AIDS 1990; 4: 687-9.

13 Friedman SL, Wright TL, Altman DF. Gastrointestinal Kaposi's sarcoma in patients with the acquired immunodeficiency syndrome - bendoscopic and autopsy findings. Gastroenterology 1985; 89: 102-8.

14 Steinberg J, Bridges N, Feiner HD, Valansi Q. Small intestinal lymphoma in three patients with acquired immunodefinal lymphoma in three patients with acquired immun

15 Bessesen MT, Wang E, Echeverria P, Blaser MJ. Enteroinvasive Escherichia coli, a cause of bacteraemia in patients with AIDS. F Clin Microbiol 1991; 29: 2675-7.

16 Kotler DP, Orenstein JM. Chronic diarrhoea and malabsorption associated with enteropathogenic bacterial infection in a patient with AIDS. Ann Intern Med 1993; 119: $127-8$.

17 Rolston KVI, Rodriguez S, Hernandez M, Bodey GP. Diarrhoea in patients infected with the human immunodeficiency virus. Am ₹ Med 1989; 86: 137-8.

18 Kelly $P$, Buve A. Chemotherapy of African AIDS diarrhoea: a preliminary study. AIDS 1993; 7: 91-3.

19 Afzalpurkar RG, Schiller LR, Santangelo WC, Fordtran JS. The self-limited nature of chronic idiopathic diarrhea. $N$ Engl f Med 1992; 327: 1849-52. 